\title{
Identification and Quantitation of Platelet-Associated
}

\section{Fibronectin Antigen}

\author{
Edward F. Plow, Charles Birdwell, and Mark H. Ginsberg with the technical \\ assistance of VICKY BYERS, LORNA TAYLOR, and Allan BRAISIER, Department \\ of Molecular Immunology and the Department of Immunopathology, The \\ Research Institute of Scripps Clinic, La Jolla, California 92037
}

\begin{abstract}
A B S T R A C T Platelet-associated fibronectin antigen has been identified by radioimmunoassay and immunofluorescent techniques. In radioimmunoassay, platelet fibronectin was immunochemically indistinguishable from plasma fibronectin. Platelet and plasma fibronectin were bound and eluted from gelatinsepharose under similar conditions. The level of platelet fibronectin in detergent extracts of washed platelets from 12 healthy adults was $2.85 \pm 1.24$ $\mu \mathrm{g} / 10^{9}$ platelets. Immunofluorescence with $\mathrm{F}\left(\mathrm{ab}^{\prime}\right)_{2}$ fragments of immunochemically purified antifibronectin showed that all platelets stained with a discrete punctate pattern. The identification of platelet fibronectin antigen raises the possibility that this protein may participate in platelet-platelet or plateletsurface interactions.
\end{abstract}

\section{INTRODUCTION}

Platelet adhesion and aggregation are fundamental events in the hemostatic process. The fibronectins (fn), ${ }^{1}$ such as cold insoluble globulin (1) and the large external transformation-sensitive protein (2), are a family of widely distributed glycoproteins found in plasma and in association with the surfaces of cells, including fibroblasts and endothelial cells $(3,4)$. This protein was originally described by Morrison et al.

This work was presented in part at the American Heart Association Meetings, Dallas, Tex. November 1978. This is publication number 1674 of Scripps Clinic and Research Foundation.

Dr. Plow is the recipient of an Established Investigatorship of the American Heart Association. Dr. Birdwell is the recipient of a Basil O'Connor Starter Research grant from the National Foundation-March of Dimes. Dr. Ginsberg is the recipient of a Clinical Investigatorship Award (AM-00393).

Received for publication 18 December 1978.

${ }^{1}$ Abbreviations used in this paper: fn, fibronectin(s); PBS, 0.14 M NaCl, 0.01 M sodium phosphate, pH 7.3; SDSPAGE, polyacrylamide gel electrophoresis in sodium dodecyl sulfate.
(1) in 1948 and has now been implicated in a wide variety of cellular activities, which primarily involve adhesion of cells to one another or to substrata. The participation of $\mathrm{fn}$ in cell agglutination, aggregation, and adhesion reactions has been demonstrated in a number of studies $(3,4)$. The presence of $\mathrm{fn}$ within the platelet was suggested by Mosesson and Umfleet (5) in 1970 but was not rigorously documented and has not been confirmed. With the increasing evidence for the role of $\mathrm{fn}$ in cell-cell interactions and the basic importance of such interactions in platelet hemostatic function, we have sought to verify the presence and quantify the level of $\mathrm{fn}$ antigen in platelets.

\section{METHODS}

Plasma fn. Plasma fn was purified by affinity chromatography on gelatin-Sepharose (Pharmacia Fine Chemicals, Piscataway, N. J.) as described by Engvall and Ruoslahti (6) with $2 \mathrm{ml}$ plasma/ml beads. Bound $\mathrm{fn}$ was eluted with either $6 \mathrm{M}$ urea, $\mathrm{pH} 7.5$ or $1 \mathrm{M} \mathrm{NaBr}, \mathrm{pH} 5.3$. The latter eluates were dialyzed against $0.14 \mathrm{M} \mathrm{NaCl}, 0.01 \mathrm{M}$ sodium phosphate, $\mathrm{pH} 7.3$ (PBS) and used for radioiodination.

Anti-fn. Anti-fn was prepared by immunization of rabbits or goats with 1-mg subcutaneous doses in complete Freund's adjuvant on a bimonthly schedule. The anti-fn used in this study was absorbed by passage through a gelatin-Sepharose column and a Sepharose column to which plasma depleted of $\mathrm{fn}$ was coupled. Fn antibodies were immunochemically purified on fn-Sepharose $(5 \mathrm{mg} \mathrm{fn} / \mathrm{ml}$ beads). After application of the antiserum and thorough washing, elution with $3.0 \mathrm{M} \mathrm{KI}$ in PBS yielded one major component of $160,000 \mathrm{~mol}$ wt on nonreduced polyacrylamide gel electrophoresis in sodium dodecyl sulfate (SDS-PAGE). $F\left(a b^{\prime}\right)_{2}$ fragments were prepared by digestion of $7.5 \mathrm{mg}$ purified antibody with $200 \mu \mathrm{g}$ of pepsin at $\mathrm{pH} 4.0$ for $18 \mathrm{~h}$ at $37^{\circ} \mathrm{C}$ followed by extensive dialysis. Control $F\left(a^{\prime}\right)_{2}$ fragments were prepared from the IgG fraction isolated by DEAEcellulose chromatography of pre-immunization bleedings. Digestion of $>97 \%$ of the IgG to $F\left(a b^{\prime}\right)_{2}$ fragments was estimated from SDS-PAGE.

Radioimmunoassay. Fn was radiolabeled with ${ }^{125} \mathrm{I}$ to a specific activity of $0.5-1 \mu \mathrm{Ci} / \mu \mathrm{g}$, and the double antibody radioimmunoassay was similar to assays previously described by this laboratory (7). Assays were performed in 
plastic, siliconized tubes at $22^{\circ} \mathrm{C}$ with ${ }^{125} \mathrm{I}-\mathrm{fn}$ at a final concentration of $15 \mathrm{ng} / \mathrm{ml}$ in a buffer system of $0.025 \mathrm{M}$ $\mathrm{NaCl}, 0.04 \mathrm{M}$ sodium borate, $\mathrm{pH} 8.3$ containing $1 \%$ heatinactivated normal rabbit serum and $1 \mathrm{mM}$ EDTA. The precipitability of the ligand in $10 \%$ trichloracetic acid was routinely $>90 \%$ and nonspecific precipitation by second antibody was $<5 \%$.

Platelets. Platelet-rich plasma was prepared as described (8) and the platelets were pelleted by centrifugation at $1,000 \mathrm{~g}$ for $20 \mathrm{~min}$ and resuspended in modified $\mathrm{Ty}$ rode's buffer (8). The suspension was then gel filtered (9) on Sepharose 2B-CL in modified Tyrode's. The washed platelets were counted electronically and exhibited typical aggregation and secretion responses to thrombin, ADP, and collagen. ${ }^{125} \mathrm{I}-\mathrm{fn}$, added to the platelet-rich plasma was not detected in the isolated platelet fraction, and, on this basis, a contribution of $\leq 200 \mathrm{ng} \mathrm{fn} / 10^{9}$ platelets caused by plasma contamination was calculated. For extraction, platelets were pelleted at $1,000 \mathrm{~g}$ for $10 \mathrm{~min}$ and $0.5 \%$ Triton $\mathrm{X}-100$ (Rohm and Haas Co., Philadelphia, Pa.) added. After 30 min at $22^{\circ} \mathrm{C}$, the supernate was retrieved by centrifugation for analysis. When isolated plasma fn was added to platelet extracts, the fn antigen was quantitatively recovered in the supernatant fraction after an 18-h incubation, indicating stability of the antigen in the extracts.

Immunofluorescence. Immunofluorescent staining was performed on $2 \%$ formaldehyde fixed platelets on polylysine-coated, circular glass cover slips. The cells were treated for $3 \mathrm{~min}$ with $0.1 \%$ Triton $\mathrm{X}-100$ to render them permeable to antibody and incubated for 20 min with either goat $\mathrm{F}\left(\mathrm{ab}^{\prime}\right)_{2}$, anti-fn, or nonimmune $\mathrm{F}\left(\mathrm{ab}^{\prime}\right)_{2}$. The cells were rinsed with $\mathrm{PBS}$ and stained for $20 \mathrm{~min}$ with rhodaminelabeled rabbit $\mathrm{F}\left(\mathrm{ab}^{\prime}\right)_{2}$ antigoat immunoglobulin (N. L. Cappel Laboratories Inc., Cochranville, Pa.). The platelets were viewed with a Zeiss universal microscope equipped with an HBO SOW mercury lamp and an IVFI epifluorescence condenser with a BP 546 excitation filter, a KT 580 chromatic splitter, and a LP 590 barrier filter (Carl Zeiss, Inc., New York).

SDS-PAGE. SDS-PAGE (10) was performed in $5 \%$ gels in the presence or absence of $1 \%$ 2-mercaptoethanol. Molecular weights were estimated from the mobility relative to protein standards.

\section{RESULTS}

The characteristics of isolated plasma fn and the antisera used in this study are shown in Fig. 1. Isolated fn, when reduced with $1 \% 2$-mercaptoethanol, revealed only a single major component on 5\% SDS-PAGE with an estimated mol wt of 230,000 (Fig. 1A). This apparent molecular weight of the $\mathrm{fn}$ subunit(s) is consistent with the reported values $(11,12)$. When radiolabeled, the reduced ${ }^{125} \mathrm{I}-\mathrm{fn}$ also migrated as a single component with a relative mobility identical to the unlabeled $\mathrm{fn}$ subunit, and $>85 \%$ of the radioactivity was recovered in the single major peak. In immunodiffusion analysis (Fig. 1B), goat anti-fn formed a single precipitin arc with normal plasma and yielded a reaction of complete identity with isolated fn. Factor VIII antigen did not form a precipitin arc with the antiserum and produced no apparent deviation of the precipitin formed with fn. In immunoelectrophoresis (Fig. 1C), anti-fn produced a single precipitin

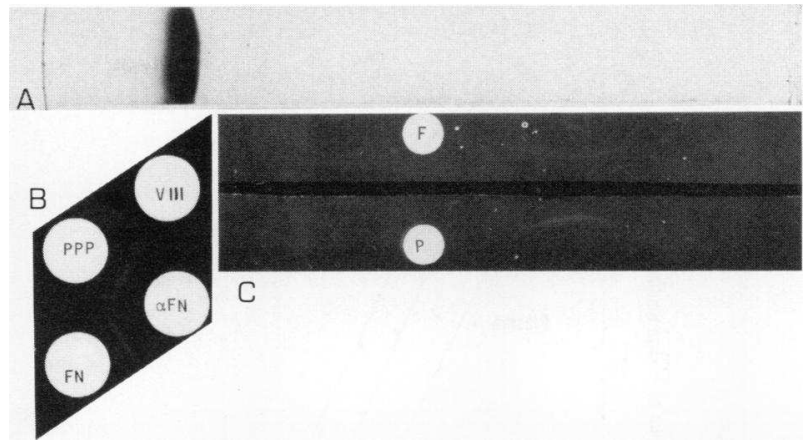

FIGURE 1 Characterization of isolated plasma fibronectin and its antiserum. (A) SDS-PAGE of isolated fn. A 25- $\mu \mathrm{g}$ sample was reduced with $1 \% 2$-mercaptoethanol and electrophoresis was performed on a $5 \%$ polyacrylamide gel. The gel was stained with Coomassie brilliant blue. (B) The double immunodiffusion analysis was performed in $1 \%$ agarose in barbital buffer, $\mathrm{pH}$ 8.6. In the wells were $12.5 \mu \mathrm{l}$ of isolated plasma fn $(300 \mu \mathrm{g} / \mathrm{ml})$, platelet-poor plasma (PPP), Factor VIII antigen ( $1 \mathrm{U} / \mathrm{ml})$, and goat anti-fn. (C) Immunoelectrophoresis was performed in $1 \%$ agarose in veronal buffer, $\mathrm{pH} 8.6$ at $5 \mathrm{~V} / \mathrm{cm}$ for $60 \mathrm{~min}$ with $3 \mu \mathrm{g}$ fn and $10 \mu \mathrm{l}$ plasma/well, and precipitins were developed with $100 \mu$ l of goat anti-fn.

arc with plasma in a position identical to purified $\mathrm{fn}$. The rabbit anti-fn used exhibited similar specificity, and in radioimmunoassay showed no binding of ${ }^{125} \mathrm{I}$ fibrinogen.

A radioimmunoassay of the double antibody type was developed to detect fn antigen in washed platelets, with isolated plasma fn as a standard for quantitation. When platelets from solutions that contained from 0.5 to $2 \times 10^{9}$ platelets $/ \mathrm{ml}$, isolated by differential centrifugation and gel filtration, were pelleted by centrifugation, $\leq 50 \mathrm{ng} / \mathrm{ml} \mathrm{fn}$ was detected in the supernates indicating minimal carryover of soluble plasma $\mathrm{fn}$. This is consistent with the failure to detect significant contamination of ${ }^{125} \mathrm{I}-\mathrm{fn}$ added to platelet-rich plasma. In contrast, fn antigen was detected in the $0.5 \%$ Triton extract of the washed platelets. (Triton alone was without effect on the assay). As shown in Fig. 2, the platelet lysate produced complete competitive inhibition as did plasma fn and plasma indicating apparent antigenic identity between the three samples. Thus, with this antiserum, platelet fn was essentially indistinguishable from plasma fn. Analysis of the platelet extract from 12 adult donors yielded an average $\mathrm{fn}$ level of $2.85 \pm 1.24$ (SD) $\mu \mathrm{g} / 10^{9}$ platelets. The range was from 1.24 to $7.20 \mu \mathrm{g} / 10^{9}$ platelets. A plasma fn level of $270 \pm 176 \mu \mathrm{g} / \mathrm{ml}$ was obtained from eight donors, consistent with reported levels (5). When platelet extracts were chromatographed on gelatinSepharose, fn antigen was bound and recovered in the $1 \mathrm{M} \mathrm{NaBr}$ eluate. Thus, the platelet fin antigen was immunochemically and functionally similar to plasma fn. 


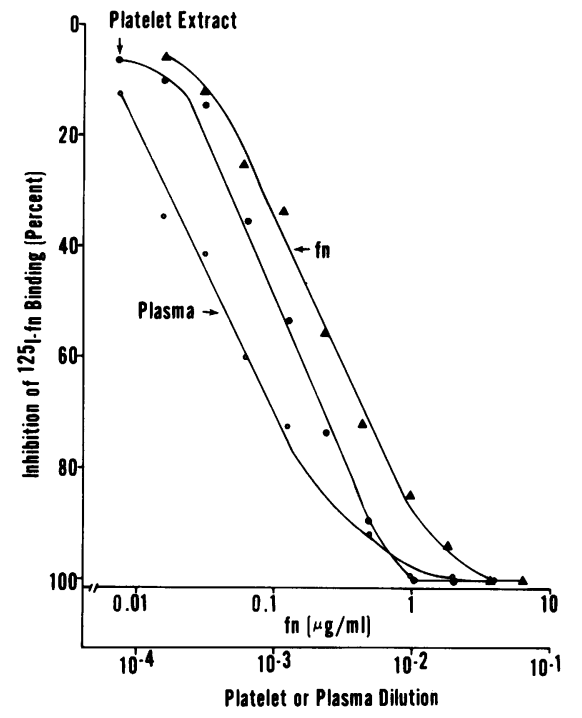

FIGURE 2 Competitive inhibition radioimmunoassay for $\mathrm{fn}$ antigen. Competing antigens were isolated plasma fn $(\boldsymbol{\Delta})$, normal plasma (O), and the Triton X-100 extract of $3 \times 10^{9}$ platelets (O). The ${ }^{125} \mathrm{I}-\mathrm{fn}$ was present at $15 \mathrm{ng} / \mathrm{ml}$ and the 1:800 dilution of rabbit anti-fn used bound $40 \%$ of the ligand.

The above experiments established that the detected fn antigen was cell associated. To determine whether the antigen was platelet derived, indirect immunofluorescent staining of the cell suspension was performed with the $\mathbf{F}\left(a b^{\prime}\right)_{2}$ fragments of immunochemically purified goat anti-fn and rhodamine-labeled $\mathrm{F}\left(\mathrm{ab}^{\prime}\right)_{2}$ fragments of rabbit anti-goat IgG. As shown in
Fig. 3, all platelets stained with the anti-fn yielded a punctate pattern with multiple discrete fluorescent foci per cell. Addition of $\mathrm{fn}$ to the antiserum before staining completely blocked cell staining, producing a pattern similar to that obtained with pre-immune $\mathrm{F}\left(\mathrm{ab}^{\prime}\right)_{2}$ fragments.

\section{DISCUSSION}

In this study, an antigen related to plasma fn has been identified in platelets. In radioimmunoassay, the plasma and platelet fn antigens were immunochemically indistinguishable, consistent with previous reports (3-5) of the immunochemical similarity of plasma and cell-associated $\mathrm{fn}$. In addition, the functional property of $\mathrm{fn}$ to bind to gelatin was also exhibited by the platelet $\mathrm{fn}$ antigen. Immunofluorescence established the identity of the fn-bearing cell as a platelet and further demonstrated that most platelets carry the antigen. The platelet $\mathrm{fn}$ antigen identified was not attributable to plasma fn contamination based upon the failure to detect ${ }^{125} \mathrm{I}-\mathrm{fn}$, added to the plateletrich plasma in the platelet fraction, or $\mathrm{fn}$ antigen in the isolated platelets before cell lysis. A number of plasma molecules including fibrinogen, Factor XIII, and Factor VIII antigen have been identified as intracellular constituents of the platelet (13). Platelets also bear receptors for molecules such as thrombin (14) and Factor $\mathrm{Xa}$ (15). The present study does not permit us to distinguish between an intracellular or a membrane-associated form of $\mathrm{fn}$.
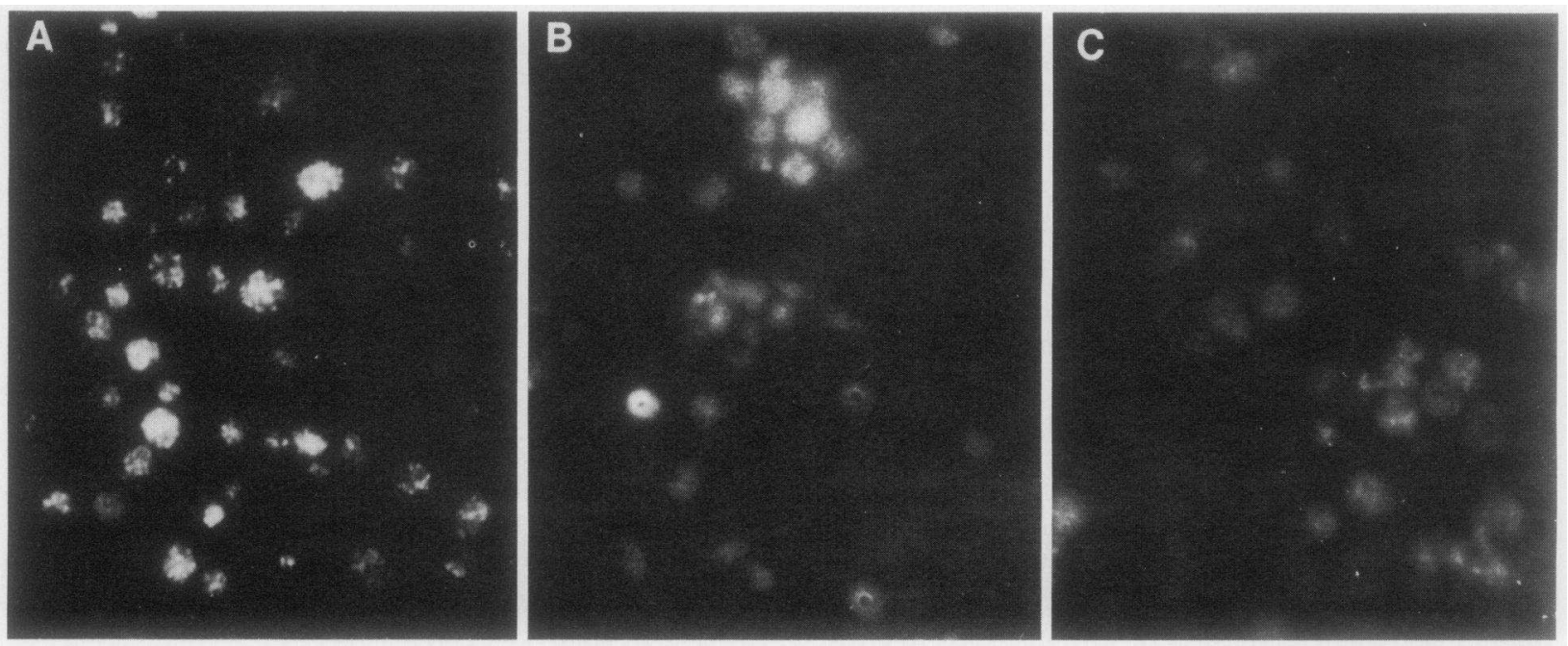

FIGURE 3 (A) Immunofluorescent staining of formaldehyde fixed and $0.1 \%$ Triton X-100 treated platelets by $\mathrm{F}\left(\mathrm{ab}^{\prime}\right)_{2}$ fragments $(50 \mu \mathrm{g} / \mathrm{ml})$ of immunochemically purified goat antiserum to $\mathrm{fn}$. The fluorescence was developed with rhodamine conjugated $\mathrm{F}\left(\mathrm{ab}^{\prime}\right)_{2}$ fragments of rabbit antiserum to goat IgG. (B) Blocking control in which an equal volume of $\mathrm{F}\left(\mathrm{ab}^{\prime}\right)_{2}$ fragments $(100 \mu \mathrm{g} / \mathrm{ml})$ of the anti-fn was incubated with isolated plasma fn $(300 \mu \mathrm{g} / \mathrm{ml})$ for $20 \mathrm{~min}$ before staining. (C) Pattern obtained with the rhodaminated antibody in the absence of anti-fn. 
The detection of platelet fn raises the possibility that certain platelet interactions may be mediated by this protein. Platelets adhere to collagen and fibrin(ogen) with induction or potentiation of platelet aggregation and release (16) and these molecules also bind to fn $(3,4,6)$. Factor XIII is present in platelets and is capable of cross-linking fn to itself or to fibrin (12). Interaction of these molecules with platelet fn either directly or after platelet stimulation might contribute to platelet-platelet and platelet-surface interactions.

\section{ACKNOWLEDGMENTS}

We gratefully acknowledge the discussions and suggestions of Dr. Deane Mosher, the gift of Factor VIII antigen from Dr. Ted Zimmerman, and the preparation of this manuscript by Mary Gortmaker and Sharon Garland.

This work was supported in part by HL-1641l and CA-23929.

\section{REFERENCES}

1. Morrison, P., R. Edsall, and S. G. Miller. 1948. Preparation and properties of serum and plasma proteins. XVIII The separation of purified fibrinogen from fractions of human plasma. J. Am. Chem. Soc. 70: 3103-3108.

2. Hynes, R. O., and J. M. Bye. 1974. Density and all cycle dependence of all surface proteins in hamster fibroblasts. Cell. 3: 113-120.

3. Yamada, K. M., and K. Olden. 1978. Fibronectins: adhesive glycoproteins of cell surface and blood. Nature (Lond.). 275: 179-184.

4. Vaheri, A., and Mosher, D. F. 1978. High molecular weight, cell surface-associated glycoprotein (fibronectin) lost in malignant transformation. Biochim. Biophys. Acta. 516: 1-25.

5. Mosesson, M. W., and R. A. Umfleet. 1970. The cold- insoluble globulin of human plasma. I. Purification, primary characterization, and relationship to fibrinogen and other cold insoluble fraction components. J. Biol. Chem. 245: 5728-5736.

6. Engvall, E., and E. Ruoslahti. 1977. Binding of soluble form of fibroblast surface protein fibronectin to collagen. Int. J. Cancer. 20: 1-5.

7. Plow, E. F., C. Hougie, and T. S. Edgington. 1971. Neoantigen expressions engendered by plasmin cleavage of fibrinogen. J. Immunol. 107: 1495-1500.

8. Ginsberg, M. H., F. Kozin, M. O'Malley, and D. J. McCarty. 1977. Release of platelet constituents by monosodium urate crystals. J. Clin. Invest. 60: 9991007.

9. Tangen, O., H. J. Berman, and P. Marfey. 1971. Gel filtration. A new technique for separation of blood platelets from plasma. Thromb. Diath. Haemorrh. 25: 268278.

10. Weber, K., and M. Osborn. 1969. The reliability of molecular weight determinations by dodecyl sulfatepolyacrylamide gel electrophoresis. J. Biol. Chem. 244: 4406-4420.

11. Mosesson, M. W., A. B. Chen, and R. M. Huseby. 1975. The cold-insoluble globulin of human plasma. Studies of its essential structural features. Biochim. Biophys. Acta. 386: 509-524.

12. Mosher, D. F. 1975. Cross-linking of cold-insoluble globulin by fibrin-stabilizing factor. J. Biol. Chem. 250: 6614-6621.

13. Niewiarowski, S. 1977. Proteins secreted by the platelet. Thromb. Haemostasis. 38: 924-938.

14. Tollefsen, D. M., J. R. Feagler, and P. W. Majerus. 1974. The binding of thrombin to the surface of human platelets. J. Biol. Chem. 249: 2646-2651.

15. Miletich, J. P., C. M. Jackson, and P. W. Majerus. 1977. Interaction of coagulation Factor Xa with human platelets. Proc. Natl. Acad. Sci. U. S. A. 74: 4033-4036.

16. Henson, P. M., M. Ginsberg, and D. C. Morrison. 1978. Mechanisms of mediator release by inflammatory cells. In Membrane Fusion. G. Poste and G. Nicholson, editors. Elsevier North-Holland, Inc., New York. 411-508. 